\title{
Retailer's Optimal Ordering Decision Based on Cost Curve
}

\author{
Heng LIU ${ }^{1}$ \\ ${ }^{1}$ School of Economics and Management, Huizhou University, Huizhou, Guangdong, 516007, China \\ LIUHENG@hzu.edu.cn
}

\begin{abstract}
In newsboy model, the relationship between unit cost and order quantity of retailer is established, and the optimal decision of retailer is given. By analyzing the optimal decision of the retailer, it is found that the optimal order quantity of the retailer based on the cost curve may be larger, smaller or equal compared with the previous optimal decision under the newsboy model; compared with the influence of cost curve parameters on the optimal order quantity, the increase of every parameters leads to the increase of the optimal order quantity; the constant term has the least influence on the optimal order quantity; for the influence of the change of the first or second coefficient of the cost function on the optimal order quantity, the retailer can choose to pay attention to one of them because of the existence of the optimal order equilibrium point. The retailer should pay attention to the influence of the change of cost curve parameters on the optimal order quantity.
\end{abstract}

Keywords: Newsboy model, Optimal order, Cost curve

\section{INTRODUCTUON}

Volatility is a common phenomenon in economic activities, such as the volatility of wholesale end and retail. A classic example of international price volatility is the crude oil futures price from 2003 to 2008, which soared from $\$ 30$ / barrel in 2003 to $\$ 147.27$ / barrel on July 14, 2008. In China, the transformation and upgrading of domestic enterprises and supply side reform have been in progress since 2016. In some domestic food markets, the price volatility is obviously different from the past. Guangdong eggs market is taken as an example. With the supply quantity increasing from 2016 to 2020 (361500 tons in 2016,385000 tons in 2017,392400 tons in 2018, 414800 tons in 2019 and 438500 tons in 2020), the egg price was different from the previous periodicity (at the end of April every year, when laying hens enter the peak laying season, the egg production will also increase significantly. Because of having more festivals in the second half of the year, resulting in a large demand for eggs, the wholesale price and retail price show seasonal weakness.).
In 2020, from the perspective of supply side, the price of farm was higher than that of wholesale price; both prices had been down all the way since the Spring Festival until May and June when both prices began to rebound, and again began to fall after reaching the peak in September as shown in Figure 1. The retail price trend of eggs in China was similar to that in Guangdong, with an amplitude of about $18 \%$ as shown in Figure 2.

The abnormal phenomenon of egg price had been aroused great concern in the market. Experts used "moulting", "chicken to capacity", "egg to replace pork in part", "COVID-19 has affected the consumption and income of residents," "speculation on idle funds" to qualitatively explain the egg prices volatility. For another example, from the end of November 2018 to the beginning of December 2021, due to the outbreak of African swine fever in China, the National Development and Reform Commission, together with a number of departments, has carried out several macro interventions on the price of pork, putting national reserves or purchasing and storing on the market. 


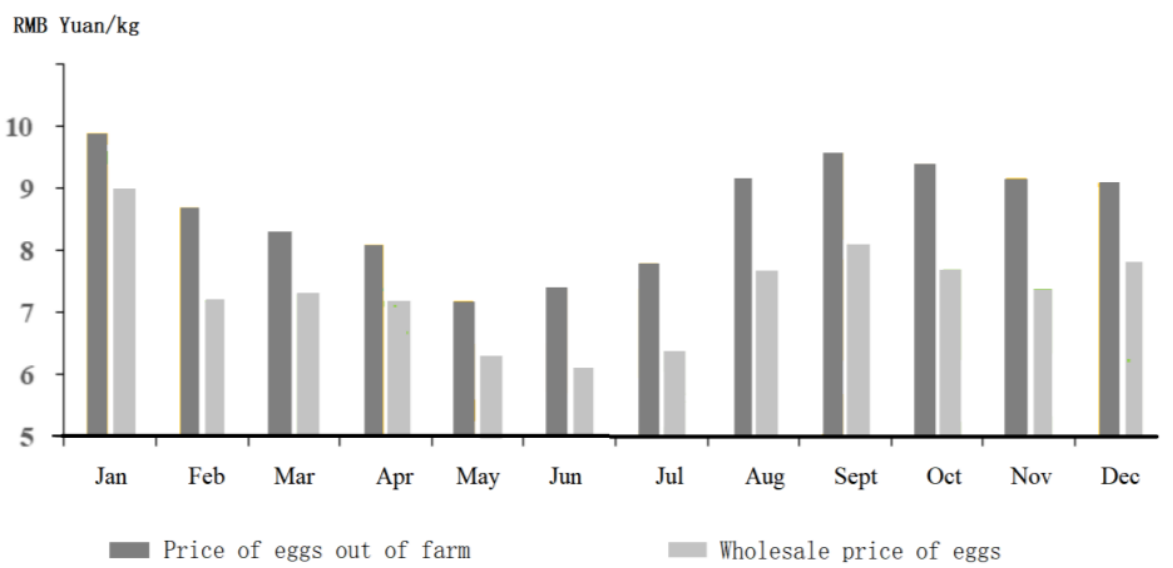

Figure 1 Price trend of eggs in Guangdong Province in 2020 (yuan / kg)

Three characteristics can be summarized from Figure 1 and Figure 2: $\square$ in terms of price cycle, the cycle is longer due to various environmental factors than before; $\square$ in a long time, the retailer has multiple cycle of orders and sales with different wholesale prices; $\square$ the wholesale price is concave function or convex function of quantity, which means that the price will fall or rise sharply over multiple cycle of orders and sales.

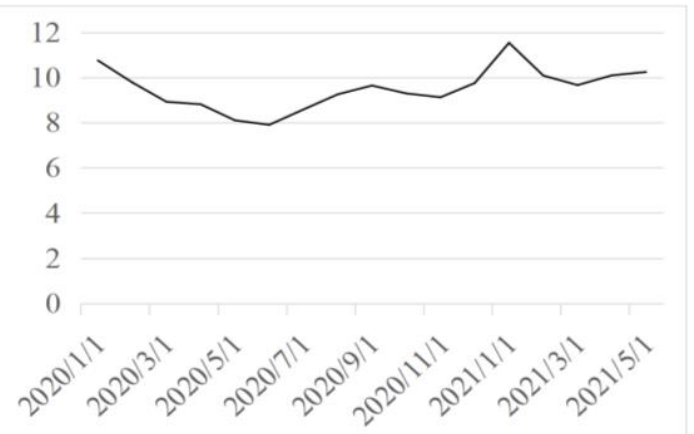

Figure 2 Current value of eggs (ordinary eggs) market price (yuan / kg)

Source: National Bureau of statistics

Because of the three characteristics, retailers cannot make orders according to their past experience (wholesale price is relatively stable), and cannot predict when the fluctuation of wholesale price will end, so face the difficult to make order decisions.

In the previous literature, the demand and cost can be dealt with as follows: demand generally is handled with linear method (the relationship between retail price and demand is linear ${ }^{[1]}{ }^{[2]}$ ) or stochastic method (retail price is exogenous variable of demand ${ }^{[3]}$ ); the cost is divided into variable cost and fixed cost, and the variable cost is equal to the wholesale price provided by the supplier. For example, the newsboy model is commonly used in FMCG decision-making ${ }^{[4-12]}$. The hypothesis in these literatures does not take into account the fluctuation of wholesale price.

In order to solve the retailer's optimal order shown above, this paper constructs the cost function on the cost side in the basis of newsboy model, gives the optimal order, and then compares it with that of classical newsboy model.

\section{MODEL CONSTRUCTION}

The process of classic newsboy model is to set in a product sales cycle. Before the sales start, the retailer purchases products from suppliers for the purpose of maximizing expected profit and make other preparations before sales, such as recruiting new employees and advertising [It is believed that advertising will directly affect the demand during the sales period, so there is a relationship coefficient between advertising fee and demand. In order to simplify the processing, the coefficient between the advertisement and the demand is not considered for the time being wait]. During the sales cycle, the retailer sells products at fixed market prices (exogenous variables). At the end of the sales cycle, the retailer process products with zero residual value and get sales revenue.

According to the characteristics of the above phenomenon and figures 1 and 2, we can reasonably infer that there is a concave or convex function relationship between wholesale price and the order quantity, so there is a functional relationship between the wholesale price and the order quantity. Based on this deduction, the cost function is constructed to reflect the relation with order quantity in the classic newsboy model.

Compared with other functions, such as exponential function, logarithmic function, trigonometric function, and so on, because the uni-variate quadratic function has a good reflection of the concave or convex function characteristics, the unit cost function is chosen as the uni-variate quadratic function.

Parameter description in the model:

$p$ is retail price in the market;

$x$ is the market demand quantity during the sales period; 
$Z$ is the order quantity of the retailer, and the superscript * indicates the best choice;

$\tau(Z)$ is the retailer's revenue at the end of the sale;

$E \tau(Z)$ is the expected retailer's revenue at the end of sale;

$c_{r}(Z)$ is the retailer's cost function, $c_{r}(Z)=a Z^{2}+b Z+C, a, b, c \in(-\infty,+\infty), \quad c_{r}(Z) \geq 0 \quad$ and the subscript $r$ denotes the retailer. Obviously, if $a=b=$ $0, c$ is the wholesale price in the classic newsboy model.

$\psi$ is the optimal order quantity of the classical newsboy model.

\section{DECISION MAKING of RETAILER}

The retailer's revenue at the end of the sale is

$$
\tau(Z)=\left\{\begin{array}{l}
p x-c_{r}(Z) Z, x<Z \\
p Z-c_{r}(Z) Z, x \geq Z
\end{array}\right.
$$

The expected retailer revenue at the end of the sale is

$$
E \tau(Z)=\int_{0}^{Z} p x f(x) d x+\int_{Z}^{+\infty} p Z f(x) d x-c_{r}(Z) Z
$$

The retailer's decision is to order optimal quantity to maximize $E \tau(Z)$.

For the first derivative of $E \tau(Z)$, we get

$$
\frac{d E \tau(Z)}{d Z}=p \int_{Z}^{+\infty} f(t) d t-\left[c_{r}(Z)+c_{r}^{\prime}(Z) Z\right]
$$

For the second derivative of $E \tau(Z)$, we get

$$
\frac{d^{2} E \tau(Z)}{d Z^{2}}=-p f(Z)-\left[2 c_{r}^{\prime}(Z)+c_{r}^{\prime \prime}(Z) Z\right]
$$

Substitute $c_{r}^{\prime}(Z)=2 a Z+b, \quad c_{r}^{\prime \prime}(Z)=2 a$ in formula (4), we get

$$
\frac{d^{2} E \tau(Z)}{d Z^{2}}=-p f(Z)-6 a Z-2 b
$$

Lemma 1: when $p f\left(Z^{*}\right)+6 a Z^{*}+2 b>0$, the retailer has the maximum expected revenue.

Lemma 2: when $\frac{c_{r}(Z)+c_{r}^{\prime}(Z) Z}{p} \in[0,1]$, the retailer has the optimal order quantity.

Then we make $\frac{d E \tau(Z)}{d Z}=0$, the optimal order quantity $Z^{*}$ obtained is satisfied with

$$
\int_{Z^{*}}^{+\infty} f(t) d t=\frac{c_{r}\left(Z^{*}\right)+c_{r}^{\prime}\left(Z^{*}\right) Z^{*}}{p}
$$

Substitute $c_{r}^{\prime}(Z)=2 a Z+b, c_{r}^{\prime \prime}(Z)=2 a$ in formula $(6)$, we get

$$
\int_{Z^{*}}^{+\infty} f(t) d t=\frac{3 a Z^{* 2}+2 b Z^{*}+C}{p}
$$

Obviously, if $a=b=0$, formula (7) is rewritten to $\int_{Z^{*}}^{+\infty} f(t) d t=\frac{C}{p}=\psi \cdot$

\section{RESULTS \& DISCUSSION}

\subsection{Results}

From formula (7), we have theorem 1 3.

Theorem 1. when $3 a Z^{*}+2 b>0$, the optimal order quantity based on cost curve is larger than that of the traditional newsboy model.

Proof: when $3 a Z^{*}+2 b>0$, we have $Z^{*}>\psi$. If $a=0$, then $b>0$. If $a>0$, then $Z^{*}>-\frac{2 b}{3 a}$, the values of $(a, b)$ are shown in the $\square$ area in Figure 2. If $a<0$, then $Z^{*}<-\frac{2 b}{3 a}$, the values of $(a, b)$ are shown in the area in Figure 3.

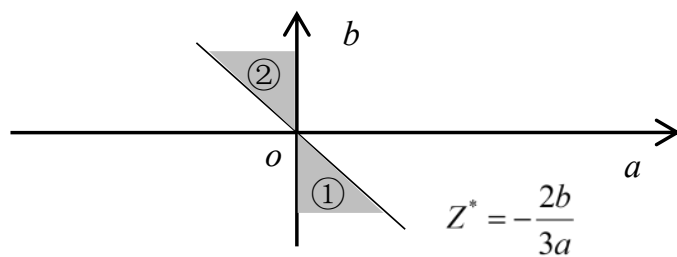

Figure 3 The order quantity based on cost curve is more than that of the classical newsboy model

Theorem 2. when $3 a Z^{*}+2 b=0$, the optimal order quantity based on cost curve is equal to the optimal order quantity of the traditional newsboy model.

Proof: when $3 a Z^{*}+2 b=0$, we have $c_{r}\left(Z^{*}\right)=C$, $Z^{*}=\psi$. If $a \neq 0$, we have $Z^{*}=-\frac{2 b}{3 a} \geq 0$, the values of $(a, b)$ are on the line $Z^{*}=-\frac{2 b}{3 a}$ shown in Figure 4.

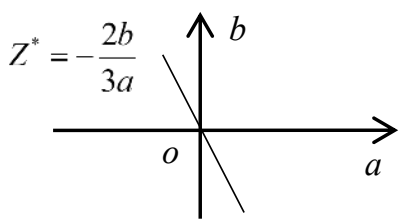

Figure 4 The order quantity based on cost curve is equal to that of classical newsboy model

Theorem 3. when $3 a Z^{*}+2 b<0$, the optimal order quantity based on cost curve is smaller than that of the traditional newsboy model.

Proof: when $3 a Z^{*}+2 b<0$, we have $Z^{*}<\psi$. If $a=0$, we have $b<0$. If $a>0$, we have $Z^{*}<-\frac{2 b}{3 a}$, 
the values of $(a, b)$ are shown in the $\square$ area in Figure 4. If $a<0$, we have $Z^{*}>-\frac{2 b}{3 a}$, the values of $(a, b)$ are shown in the $\square$ area in Figure 5.

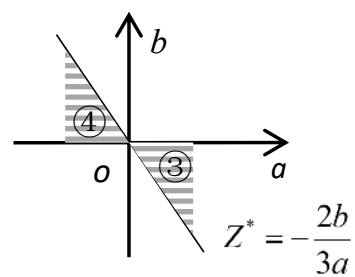

Figure 5 The order quantity based on the cost curve is less than that of the classical newsboy model

We synthesize Figure $3 \sim$ Figure 5 to get Figure 6 . In Figure 6, the retailer can know whether the optimal order quantity is more than, equal to or less than that in the classical newsboy model by knowing the area of $a$ and $b$ values. Obviously, when $(a, b)$ is in the blank area in Figure 6, it means the optimal order quantity in the classical newsboy model does not exist.

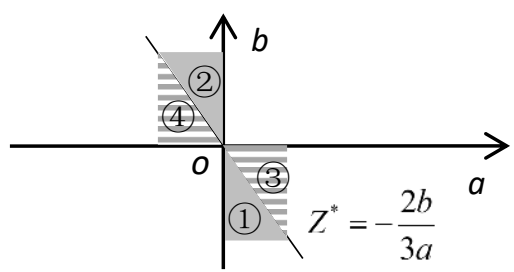

Figure 6 Comparison between the order quantity based on cost curve and the optimal order quantity of classical newsboy mode

\subsection{Discussion}

We discuss the influence of coefficient change in cost curve on optimal order quantity, then we have theorem 4 9.

Theorem 4. The optimal order quantity increases with the increase of $a$.

Proof: for $Z^{*}$, we get the first derivative of $a$, then

$$
\frac{\partial Z^{*}}{\partial a}=-\frac{3 Z^{* 2}}{p f\left(Z^{*}\right)+6 a Z^{*}+2 b}
$$

Because of $Z^{* 2} \geq 0$, according to lemma 1 : $p f\left(Z^{*}\right)+6 a Z^{*}+2 b>0$, then $Z^{*}$ increases with the increase of $a$.

Theorem 5. The optimal order quantity increases with the increase of $b$.

Proof: for $Z^{*}$, we get the first derivative of $b$, then

$$
\frac{\partial Z^{*}}{\partial b}=-\frac{2 Z^{*}}{p f\left(Z^{*}\right)+6 a Z^{*}+2 b}
$$

Because of $Z^{*}>0$, according to lemma 1 : $p f\left(Z^{*}\right)+6 a Z^{*}+2 b>0$, then $Z^{*}$ increases with the increase of $b$.

Theorem 6. The optimal order quantity increases with the increase of $c$.

Proof: for $Z^{*}$, we get the first derivative of $c$, then

$$
\frac{\partial Z^{*}}{\partial c}=-\frac{1}{p f\left(Z^{*}\right)+6 a Z^{*}+2 b}
$$

Because of $Z^{*}>0$, according to lemma 1: $p f\left(Z^{*}\right)+6 a Z^{*}+2 b>0$, then $Z^{*}$ increases with the increase of $c$.

Theorem 7. The influence of $a$ changing on the optimal order quantity is greater than that of $c$ changing.

Proof: for $Z^{*}$, the relationship between $a$ and $c$, because of $Z^{*} \geq 0$, we have

$$
\frac{\partial a}{\partial c}=\frac{\partial Z^{*}}{\partial c} / \frac{\partial Z^{*}}{\partial a}=\frac{1}{2 Z^{*}}>0
$$

$\frac{\partial a}{\partial c}>0$ means that the influence of a changing on the optimal order quantity is greater than that of $c$ changing.

Theorem 8. The influence of $b$ changing on the optimal order quantity is greater than that of $c$ changing.

Proof: for $Z^{*}$, the relationship between $b$ and $c$, because of $Z^{*}>0$, we have

$$
\frac{\partial b}{\partial c}=\frac{\partial Z^{*}}{\partial c} / \frac{\partial Z^{*}}{\partial b}=\frac{1}{3 Z^{* 2}}>0
$$

$\frac{\partial b}{\partial c}>0$ means that the influence of $b$ changing on the optimal order quantity is greater than that of $c$ changing.

Theorem 9. When $Z^{*} \geq \frac{2}{3}$, with the increase of $c$, the influence of $a$ changing on the optimal order quantity is greater than that of $b$ changing; when $Z^{*}<\frac{2}{3}$, with the increase of $c$, the influence of $a$ changing on the optimal order quantity is less than that of $b$ changing.

Proof: for $Z^{*}$, the relationship between $\frac{\partial a}{\partial c}$ and $\frac{\partial b}{\partial c}$, we have

$$
\frac{\partial a}{\partial c}-\frac{\partial b}{\partial c}=\frac{1}{2 Z^{*}}-\frac{1}{3 Z^{* 2}}=\frac{3 Z^{*}-2}{6 Z^{* 2}}
$$

When $Z^{*} \geq \frac{2}{3}$, we have $\frac{\partial a}{\partial c}-\frac{\partial b}{\partial c} \geq 0$, which means that the influence of $a$ changing on the optimal order quantity is greater than that of $b$ changing. When 
$Z^{*}<\frac{2}{3}$, we have $\frac{\partial a}{\partial c}-\frac{\partial b}{\partial c}<0$, which means that the influence of $a$ changing on the optimal order quantity is less than that of $b$ changing.

It can be understood that $Z^{*}=\frac{2}{3}$ is the optimal order equilibrium point the retailer concerned about of the coefficient of $a$ or $b$. when $Z^{*} \geq \frac{2}{3}$, retailers should first pay attention to the change of quadratic coefficient $a$, otherwise the retailer should first pay attention to the change of the first term coefficient $b$.

\section{CONCLUSION}

In the newsboy model, a quadratic linear relationship between retailer's cost side and order quantity is constructed, and the optimal decision of retailer is given. By analyzing the optimal decision of the retailer, it is found that the optimal order quantity of the retailer based on the cost curve may be larger, smaller or equal compared with the previous optimal decision under the newsboy model; compared with the influence of cost curve parameters on the optimal order quantity, the increase of every parameters leads to the increase of the optimal order quantity; the constant term has the least influence on the optimal order quantity; for the influence of the change of the first or second coefficient of the cost function on the optimal order quantity, the retailer can choose to pay attention to one of them because of the existence of the optimal order equilibrium point.

Future research can consider whether there is coordination contract between retailer and supplier based on cost curve, and optimal decision of risk preference retailer based on cost curve, and optimal decision based on information asymmetry between retailer and supplier.

\section{ACKNOWLEDGMENTS}

Supported by the Huizhou University Project (C512-0103)

\section{REFERENCES}

[1] ZHOU Ming-yang, LIN Jie, YUAN Yue-yun. Research on advertising and pricing models in manufacturer-retailer supply chains [J]. Soft Science, 2014, 28(7): 29-33(In Chinese).

[2] HU Gang, QIN Pei-pei. Contrastive analysis of supply chain decision model considering advertising input under different sales strategies [J]. Journal of University of South China ( Social Science Edition), 2019, 20 (3): 64-69 (In Chinese).
[3] YI Yu-yin, XU Qing-qing. Closed-loop supply chain model with advertising and uncertain demand $[\mathrm{J}]$. Computer Integrated Manufacturing Systems, 2011, 17 (9): 2005-2014 (In Chinese).

[4] M. Schweitzer, G. Cachon. Decision bias in the news vendor problem with a known demand distribution: Experimental evidence [J]. Management Science, 2000, 46(3): 404-420.

[5] G. Cachon, S. Netessine. Game theory in supply chain analysis[Z]. An invited chapter for the book ' Supply chain analysis in the e-business era' [M], Kluwer, 2003.

[6] ZOU Qing-ming, CHEN Jian-hua, YE Guang-yu. Pricing strategies and coordination mechanism of closed-loop supply chain considering product design and quality of recovery products [J]. Systems Engineering, 2017, (5). 140-144 (In Chinese).

[7] TIAN Li-ping, JIA Peng-fei, YAN Bin-bin. The combined contract model of perishable goods supply chain with consideration of return price [J]. Mathematics in Practice and Theory, 2015(21): 107-113(In Chinese).

[8] QIN Yan-hua. Closed-loop supply chain coordination under selling market and recycling market disruptions [J]. Operations Research and Management Science, 2015(5): 52-56(In Chinese).

[9] HAO Xin-jun. Research on contract coordination of closed-loop supply chain with enterprise's different risk preference [D]. Chang'an University, 2018.

[10] MA Shi-hua, ZHOU Qi-chao, GUAN Xu. Research on the supply chain coordination of the incentive buyback contract and advertising investment $[\mathrm{J}]$. Industrial Engineering and Management, 2011,16(5): 16-21 (In Chinese).

[11] ZHOU Yong-wu, XIAO Dan, LI Ji-cai. Joint decision-making of order quantities and advertising expenditure for loss-averse retailers [J]. Systems Engineering-Theory \& Practice, 2012, 32(8): 1727-1738 (In Chinese).

[12] ZHANG Li-na, LIU Gui-qing, LIN Guan-nan. Study of joint advertising investment and order policy in a supply chain under Profit-CVaR criterion $[\mathrm{J}]$. Journal of Hefei University of Technology (Natural Science), 2015, (2): 258-263(In Chinese). 